\title{
Memory Deficits of British Dementia Knock-In Mice Are Prevented by A $\beta$-Precursor Protein Haploinsufficiency
}

\author{
Robert Tamayev ${ }^{1}$ and Luciano D’Adamio ${ }^{1,2}$ \\ ${ }^{1}$ Department of Microbiology and Immunology, Albert Einstein College of Medicine, Bronx, New York 10461, and ${ }^{2}$ National Research Council of \\ Italy-Cellular Biology and Neurobiology Institute, 00143 Rome, Italy
}

Familial British Dementia (FBD) is caused by an autosomal dominant mutation in the BRI2/ITM2B gene (Vidal et al., 1999). FBD $_{\mathrm{KI}}$ mice are a model of FBD that is genetically congruous to the human disease, because they carry one mutant and one wild-type Bri2/Itm $2 b$ allele. Analysis of these mice has shown that the British mutation causes memory impairments due to loss of Bri2 function (Tamayev et al., $2010 \mathrm{~b}) . \mathrm{BRI} 2$ is a physiologic inhibitor of processing of the $\mathrm{A} \beta$-precursor protein (APP; Matsuda et al., 2008), a gene associated with Alzheimer's disease (Bertram et al., 2010). Here we show that $A P P$ haploinsufficiency prevents memory dysfunctions seen in $\mathrm{FBD}_{\mathrm{KI}}$ mice. This genetic suppression is consistent with a role for APP in the pathogenesis of memory deficits. Moreover, it provides compelling evidence that the memory dysfunctions caused by the British BRI2 mutant are dependent on endogenous APP and that BRI2 and APP functionally interact. This evidence establishes a mechanistic connection between Familial British and Alzheimer's dementias.

\section{Introduction}

Familial British Dementia (FBD) is an autosomal dominant neurodegenerative disease characterized by the early onset of personality changes, memory and cognitive deficits, spastic rigidity, and ataxia, which is caused by a mutation in the BRI2/ITM $2 B$ gene (Vidal et al., 1999). BRI2 is a type II membrane protein of 266 aa that is cleaved at the $\mathrm{C}$ terminus into a peptide of 23 aa (Bri23) plus a membrane-bound mature BRI2 product (Kim et al., 2002; Choi et al., 2004). In FBD patients, a point mutation at the stop codon of BRI2 results in a read-through of the $3^{\prime}$-untranslated region and the synthesis of a BRI2 molecule containing 11 extra amino acids at the $\mathrm{COOH}$ terminus. Cleavage by convertases generates a longer peptide, the ABri peptide, which is deposited as amyloid fibrils. FBD and Alzheimer's patients share common neuropathology including neurodegeneration, amyloid, and neurofibrillary tangles (Vidal et al., 2000; Holton et al., 2001, 2002; Rostagno et al., 2002).

To study the pathogenesis of $\mathrm{FBD}$, we have generated $\mathrm{FBD}_{\mathrm{KI}}$ mice (Tamayev et al., 2010b). In these knock-in mice, the pathogenic human mutation is inserted in the mouse allele. Thus, this knock-in model is genetically faithful to the human disease.

Received Oct. 13, 2011; revised Feb. 10, 2012; accepted March 1, 2012

Author contributions: L.D. designed research; R.T. and L.D. performed research; R.T. and L.D. analyzed data; L.D. wrote the paper.

This work was supported by grants from the Alzheimer's Association (IIRG-09-129984 and ZEN-11-201425), the National Institutes of Health (R01AG033007), a Thome Foundation grant to L.D, and Training Program in Cellular and Molecular Biology and Genetics Grant T32 GM007491 supporting R.T. We thank Alessia P. M. Barbagallo for technical help.

L.D. is an inventor of a patent on the $\mathrm{FBD}_{\mathrm{KI}}$ mice. The assign is the Albert Einstein College of Medicine. The Albert Einstein College of Medicine has licensed the patent to a Biotech company (Remegenix) of which L.D. is a cofounder.

Correspondence should be addressed to Luciano D'Adamio, National Research Council of Italy, Cellular

Biology and Neurobiology Institute, Via del Fosso del Fiorano, 64, 00143 Roma, Italy. E-mail: luciano.dadamio@einstein.yu.edu.

DOI:10.1523/JNEUROSCI.5193-11.2012

Copyright $\odot 2012$ the authors $\quad 0270-6474 / 12 / 325481-05 \$ 15.00 / 0$
$\mathrm{FBD}_{\mathrm{KI}}$ mice present severe memory impairments, which are evident at 9 months of age. Interestingly, these mice never develop measurable amyloid lesion or tauopathy (Tamayev et al., 2010b). These memory deficits are instead associated with depletion of mature Bri2 protein levels in $\mathrm{FBD}_{\mathrm{KI}}$ mice. Of note, a similar decrease in mature BRI2 has also been observed in brain samples from FBD patients (Tamayev et al., 2010b). These data suggested to us that loss of BRI2 function, rather than amyloidosis, plays a prominent role in the pathogenesis of memory loss in FBD. The evidence that Bri2/Itmb2 haploinsufficient mice present memory deficits similar to $\mathrm{FBD}_{\mathrm{KI}}$ mice (Tamayev et al., 2010a,b) supports this hypothesis.

BRI2 is a physiological interactor of APP and regulates APP metabolism (Fotinopoulou et al., 2005; Matsuda et al., 2005, 2008, 2011b; Kim et al., 2008; Kilger et al., 2011). Since APP plays a central role in Alzheimer's disease (AD) pathogenesis and mutations in APP cause familial forms of AD (Bertram et al., 2010) we postulated that APP mediates memory impairments caused by loss of BRI2 function in FBD. Here we have investigated this hypothesis.

\section{Materials and Methods}

Mouse handling

Mice were handled according to the Ethical Guidelines for Treatment of Laboratory Animals of Albert Einstein College of Medicine. The procedures were described and approved in animal protocol number 200404.

\section{Behavior}

The animals used for these studies were backcrossed to C57BL/6J mice for at least 14 generations. Only male mice were used to avoid variations due to hormonal fluctuations during the female estrous cycle, which influence severely behavioral and electrophysiological tests.

\section{Spatial working memory}

The task studied with the radial arm water maze (RAWM) test has been described previously (Trinchese et al., 2004). The scores for each mouse 
on the last $3 \mathrm{~d}$ of testing were averaged and used for statistical analysis. Briefly, a six-armed maze was placed into a white tank filled with water $\left(24-25^{\circ} \mathrm{C}\right)$ and made opaque by the addition of nontoxic white paint. Spatial cues were presented on the walls of the testing room. At the end of one of the arms was positioned a clear $10 \mathrm{~cm}$ submerged platform that remained in the same location for every trial in $1 \mathrm{~d}$ but was moved approximately randomly from day to day. On each trial, the mouse started the task from a different randomly chosen arm. Each trial lasted $1 \mathrm{~min}$, and errors were counted each time the mouse entered the wrong arm or needed $>10$ s to reach the platform. After each error, the mouse was pulled back to its starting position. After four consecutive acquisition trials, the mouse was placed in its home cage for $30 \mathrm{~min}$, then returned to the maze and administered a fifth retention trial.

Visible platform. Visible platform training to test visual and motor deficits was performed in the same pool as in the RAWM; however, the arms of the maze were removed. The platform was marked with a black flag and positioned randomly from trial to trial. Time to reach the platform and speed were recorded with a video tracking system (HVS 2020; HVS Image).

Open field and novel object recognition. After $30 \mathrm{~min}$ to acclimate to the testing room, each mouse was placed into a $40 \times 40 \mathrm{~cm}$ open field chamber with 2 -foot-high opaque walls. Each mouse was allowed to habituate to the normal open field box for $10 \mathrm{~min}$, and repeated again $24 \mathrm{~h}$ later, in which the video tracking system (HVS 2020; HVS Image) quantifies the number of entries into and time spent in the center of the locomotor arena. Novel object recognition was performed as previously described (Bevins and Besheer, 2006). Results were recorded as an object discrimination ratio, which is calculated by dividing the time the mice spent exploring the novel object, divided by the total amount of time exploring the two objects.

\section{Statistical analysis}

All data are shown as mean \pm SEM. Experiments were performed in blind. Statistical tests included using the $t$ test when appropriate.

\section{Homogenates and synaptic membranes preparation}

Hippocampal samples from $\mathrm{FBD}_{\mathrm{KI}}$ mice and WT littermates were prepared by homogenizing the hippocampus ( $\mathrm{w} / \mathrm{v}=10 \mathrm{mg}$ tissue $/ 100 \mathrm{ml}$ buffer) in HEPES-sucrose buffer (20 mM HEPES/NaOH pH 7.4, $1 \mathrm{~mm}$ EDTA, $1 \mathrm{~mm}$ EGTA, and $0.25 \mathrm{~m}$ sucrose) supplemented with protease and phosphatase inhibitors. Homogenates were centrifuged at $800 \times g$ for $10 \mathrm{~min}$. The supernatant (S1) was separated into supernatant (S2) and pellet (P2) by spinning at $9200 \times g$ for $15 \mathrm{~min}$. P2 was lysed on ice for $30 \mathrm{~min}$ in HEPES buffer (20 mm HEPES/NaOH pH 7.4, 1 mM EDTA, and $1 \mathrm{~mm}$ EGTA) containing $35.6 \mathrm{~mm}$ sucrose. The lysed P2 was separated into supernatant (LS1) and pellet (LP1) by spinning at $25,000 \times g$ for $20 \mathrm{~min}$.

\section{Antibodies}

The following antibodies were used: $\alpha$-APP (22C11, Millipore MAB348); $\alpha$-APP C-terminal fragments (CTF; Invitrogen/Zymed 36-6900); anti$\alpha$-tubulin (Sigma 111DM1A); $\alpha$-BRI2 (Santa Cruz Biotechnology).

\section{Results}

APP mediates the recognition memory deficit of $\mathrm{FBD}_{\mathrm{KI}}$ mice $\mathrm{FBD}_{\mathrm{KI}}$ mice develop severe memory deficits that are evident at $\sim 9$ months of age (Tamayev et al., 2010b). These deficits are attributable to loss of mature BRI2 protein caused by the FBD

\section{B}

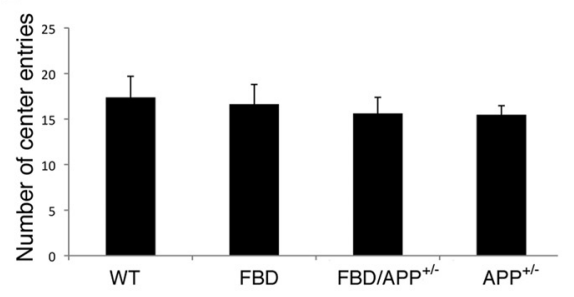

D

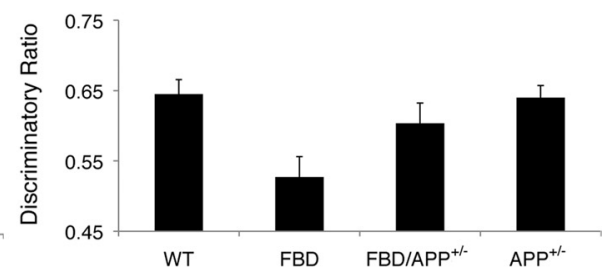
characterized function of BRI2 is to bind to and regulate the processing of APP, and because APP plays a central role in the pathogenesis of $A D$, we tested whether APP mediates the memory deficits of $\mathrm{FBD}_{\mathrm{KI}}$ mice. To do this, we used a genetic approach in which we tested whether reducing APP load would prevent memory loss in $\mathrm{FBD}_{\mathrm{KI}}$ mice. Nine-month-old WT, $A P P^{+/-}$, $\mathrm{FBD}_{\mathrm{KI}}, \mathrm{FBD}_{\mathrm{KI}} / A P P^{+/-}$mice were first subjected to the standard Open Field test, which is commonly used to assess locomotor, exploratory, and anxiety-like behavior in laboratory animals (rats/mice). The Open Field area consists of an empty and bright square arena, surrounded by walls to prevent the animal from escaping. The animal is placed in the center of the arena and its behavior recorded over a chosen period of $10 \mathrm{~min}$. The Open Field task approaches the conflict between the innate fear that rodents have of the central area of a novel or brightly lit open field versus their desire to explore new environments. When anxious, the natural tendency of rodents is to prefer staying close to the walls (thigmotaxis). In this context, anxiety-related behavior is measured by the degree to which mice avoid the center of the Open Field test. The results showed that the four genotypes spent similar amounts of time in the center (WT vs $\mathrm{FBD}_{\mathrm{KI}}, p=0.59$; WT vs $\mathrm{FBD}_{\mathrm{KI}} / A P P^{+/-}, p=0.99 ; \mathrm{WT} \mathrm{vs} A P P^{+/-}, p=0.47 ; \mathrm{FBD}_{\mathrm{KI}}$ vs $\mathrm{FBD}_{\mathrm{KI}} / A P P^{+/-}, p=0.60 ; \mathrm{FBD}$ vs $A P P^{+/-}, p=0.91 ; \mathrm{FBD}_{\mathrm{KI}} \mathrm{I}$ $A P P^{+/-}$vs $A P P^{+/-}, p=0.51$, Fig. $\left.1 A\right)$ and that they entered the center the same number of times (WT vs $\mathrm{FBD}_{\mathrm{KI}}, p=0.74$; WT vs $\mathrm{FBD}_{\mathrm{KI}} / A P P^{+/-}, p=0.36$; WT vs $A P P^{+/-}, p=0.28 ; \mathrm{FBD}_{\mathrm{KI}}$ vs $\mathrm{FBD}_{\mathrm{KI}} / A P P^{+/-}, p=0.60 ; \mathrm{FBD}$ vs $A P P^{+/-}, p=0.49 ; \mathrm{FBD}_{\mathrm{KI}} /$ $A P P^{+/-}$vs $A P P^{+/-}, p=0.92$, Fig. $\left.1 B\right)$. Moreover, WT and $\mathrm{FBD}_{\mathrm{KI}}$ mice showed similar total track lengths $(p=0.94)$ and vertical activity $(p=0.76)$.

After the open field studies showed that $A P P^{+/-}, \mathrm{FBD}_{\mathrm{KI}}$, $\mathrm{FBD}_{\mathrm{KI}} / A P P^{+/-}$mice have no defects in habituation and locomotor behavior, and anxiety-like behavior in novel environments, 


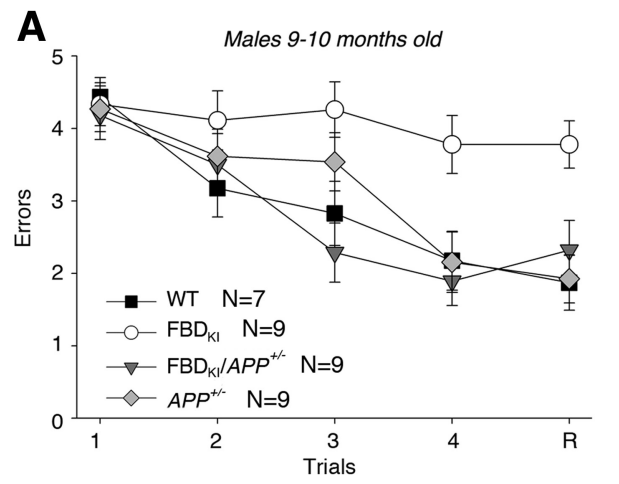

B

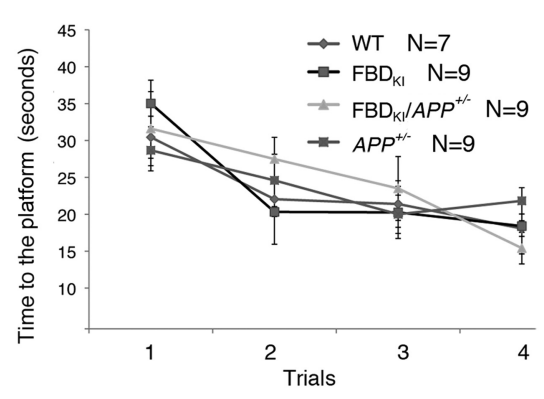

E 200

${ }^{200}$

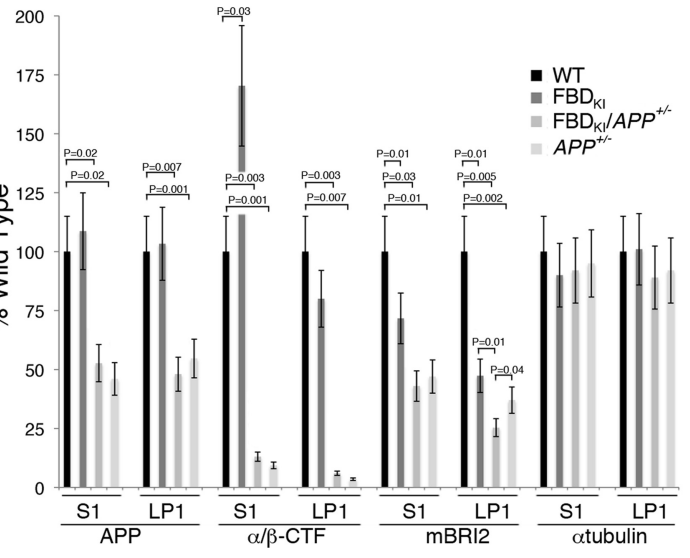

Figure 2. APP haploinsufficiency prevents the working-memory deficits of $F B D_{\mathrm{KI}}$ mice. $A$, In $\mathrm{RAWM}$ testing, $A P P^{+/-}$and $\mathrm{FBD}_{\mathrm{KI}} / A P P^{+/-}$mice made the same number of errors as $W T$ mice. $F B D_{\mathrm{KI}}$ mice made significantly more errors at $\mathrm{A} 3$ (vs FBD $\mathrm{KI}_{\mathrm{KI}} / \mathrm{APP}^{+/-} p=0.0008$; vs WT $p=0.018$ ), $\mathrm{A} 4$ (vs $A P P^{+/-} p=0.0075 ; \mathrm{vs} \mathrm{FBD}_{\mathrm{KI}} / A P P^{+/-} p=0.0006$; vs WT, $p=0.0074$ ) and R (vs $A P p^{+/-} p=$

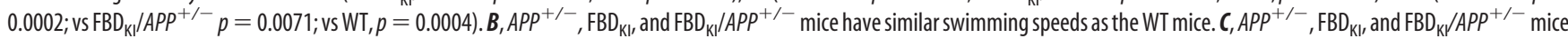
needed similar time to reach a visible platform. Overall, the data show that $A P P$ haploinsufficiency prevents the insurgence of working memory deficits in $\mathrm{FBD}_{\mathrm{KI}}$ mice. $D, A P P, \beta$-CTF, and $\alpha$-CTF levels are reduced in both $\mathrm{S} 1$ and $\mathrm{LP} 1$ fractions of $\mathrm{FBD}_{\mathrm{KI}} / \mathrm{APP}^{+/-}$and $A P P^{+/-}$mice. Mature BRI2 levels are reduced in $\mathrm{FBD}_{\mathrm{KI}}$ mice, as previously reported. Surprisingly mBRI2 expression in halved in $A P P^{+/-}$mice and further reduced in synaptic membranes of $\mathrm{FBD}_{\mathrm{KI}} / A P P^{+/-}$animals. E, Quantization of triplicates. The expression of each protein in the WT sample has been set to an arbitrary value of 100. Expression of the same protein in the same fraction of the other genotypes has been expressed as a percentage of the WT levels.

WT Normal memory Impaired memory
A

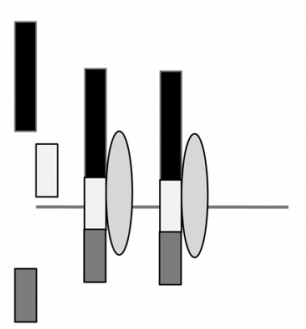

B

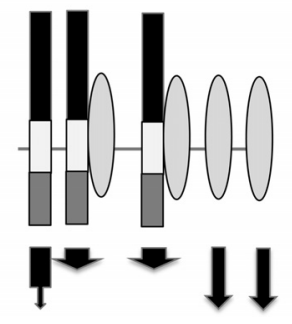

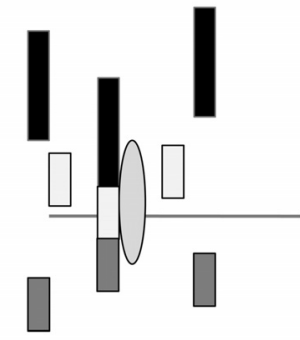

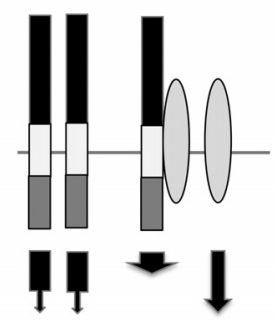

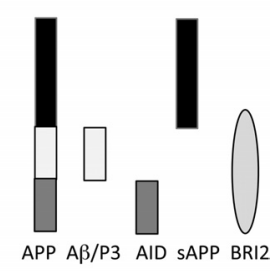

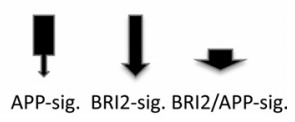

Figure 3. Models depicting the mechanisms by which APP leads to memory deficits in FBD. $A$, In this model, memory deficits in FBD are caused by the increased production of toxic APP-derived metabolites due to loss of inhibitory function of APP processing by BRI2. Bri2, APP, and the APP derived metabolites [soluble APP (SAPP), A $\beta, P 3$, and the APP intracellular domain (AID)] are schematically represented. $\boldsymbol{B}$, Alternatively, membrane bound BRI2, APP, and APP/BRI2 complexes could regulate distinct signaling pathways (indicated as APP-sig., BRI2-sig., and BRI2/APP-sig.). In FBD, the reduction of BRI2 levels result in a "signaling unbalance" leading to synaptic and memory dysfunction. we tested memory using novel object recognition (NOR), a nonaversive task that relies on the mouse's natural exploratory behavior. During the training session, mice of all genotypes spent the same amount of time exploring the two identical objects (Fig. 1C). The following day, when a novel object was introduced, FB$\mathrm{D}_{\mathrm{KI}}$ spent the same amount of time exploring the two objects as if they were both novel to them, while the WT and $A P P^{+/-}$ mice still spent more time exploring the novel object (Fig. $1 D$ ). Notably, $\mathrm{FBD}_{\mathrm{KI}} /$ $A P P^{+/-}$mice behaved like the WT mice and explored preferentially the novel object (Fig. 1D). These data confirm that memory is impaired in $\mathrm{FBD}_{\mathrm{KI}}$ mice upon aging in an ethologically relevant, nonaversive behavioral context; remarkably, development of this deficit is fully prevented by $A P P$ haploinsufficiency.

The short-term memory deficit of $\mathrm{FBD}_{\mathrm{KI}}$ mice is mediated by APP

Next, we performed a spatial working memory test such as the RAWM, which depends upon hippocampal function (Di- 
amond et al., 1999) and tests short-term memory, a type of memory that is affected at early stages of AD. Mice were required to learn and memorize the location of a hidden platform in one of the arms of a maze with respect to spatial cues. WT and $A P P^{+/-}$ mice were able to acquire $(\mathrm{A})$ and retain $(\mathrm{R})$ memory of the task. $\mathrm{FBD}_{\mathrm{KI}}$ mice showed severe abnormalities during both acquisition and retention of the task (Fig. $2 A$ ), confirming that $\mathrm{FBD}_{\mathrm{KI}}$ mice have severe impairment in short-term spatial memory for platform location during both acquisition and retention of the task. Once again, halving APP expression prevented the development of short-term spatial memory in $\mathrm{FBD}_{\mathrm{KI}}$ mice (Fig. 2). Importantly, none of the four genotypes showed an anxiety phenotype and the absence of search behavior such as floating or thigmotaxis (swimming constantly along the perimeter of the pool).

A visible platform test was performed to determine whether genotypic manipulations resulted in crude alterations in visual acuity and/or locomotory activity that might confound the analyses of data that depend on the use of distal visual cues and swimming ability for task performance. Testing with the visible platform showed no difference in the time needed to find the platform (WT vs $\mathrm{FBD}_{\mathrm{KI}}, p=0.89$; WT vs $\mathrm{FBD}_{\mathrm{KI}} / A P P^{+/-}, p=$ 0.36 ; WT vs $A P P^{+/-}, p=0.38 ; \mathrm{FBD}_{\mathrm{KI}}$ vs $\mathrm{FBD}_{\mathrm{KI}} / A P P^{+/-}$, $p=0.37 ; \mathrm{FBD}$ vs $A P P^{+/-}, p=0.48 ; \mathrm{FBD}_{\mathrm{KI}} / A P P^{+/-}$vs $A P P^{+/-}$, $p=0.91$; Fig. $2 B$ ), and swimming speed (WT vs $\mathrm{FBD}_{\mathrm{KI}}, p=0.20$; WT vs $\mathrm{FBD}_{\mathrm{KI}} / A P P^{+/-}, p=0.77 ; \mathrm{WT}$ vs $A P P^{+/-}, p=0.53 ; \mathrm{FBD}_{\mathrm{KI}}$ vs $\mathrm{FBD}_{\mathrm{KI}} / A P P^{+/-}, p=0.48 ; \mathrm{FBD}$ vs $A P P^{+/-}, p=0.74 ; \mathrm{FBD}_{\mathrm{KI}} /$ $A P P^{+/-}$vs $A P P^{+/-}, p=0.73$; Fig. $2 C$ ), among the four genotypes. Thus, the RAWM deficits of $\mathrm{FBD}_{\mathrm{KI}}$ are a deficit in memory per se and are not due to deficits in vision, motor coordination, or motivation. Together, these findings provide compelling genetic evidence that APP and BRI2 functionally interact, and that the synaptic and memory deficiencies due to loss of Bri2 function in $\mathrm{FBD}_{\mathrm{KI}}$ mice only occur when sufficient levels of APP are supplied.

To verify that APP hemizygosity results in halving APP expression, we prepared hippocampal total lysates $(\mathrm{S} 1)$ and purified synaptic membrane fractions (LP1) from WT, $A P P^{+/-}, \mathrm{FBD}_{\mathrm{KI}}$, and $\mathrm{FBD}_{\mathrm{KI}} / A P P^{+/-}$mice. As shown in Figure 2, $D$ and $E$, APP levels were reduced by $\sim 50 \%$ in $A P P^{+/-}$and $\mathrm{FBD}_{\mathrm{KI}} / A P P^{+/-}$ mice compared with WT littermates, both in S1 and synaptic membrane fractions. As expected, $\mathrm{WT}$ and $\mathrm{FBD}_{\mathrm{KI}}$ expressed similar levels of APP. We also tested the expression levels of $\beta$-CTF and $\alpha$-CTF, the two C-terminal fragments derived from cleavage of APP by $\beta$ - and $\alpha$-secretases, respectively. First, we noticed that $\alpha / \beta$-CTFs are significantly enriched in synaptic membrane fractions compared with total lysates. Moreover, we found a $\sim 90 \%$ and $\sim 95 \%$ reduction in $\alpha / \beta$-CTFs in S1 and LP1 preparations from $A P P^{+/-}$and $\mathrm{FBD}_{\mathrm{KI}} / A P P^{+/-}$mice (Fig. $2 D, E$ ). Why this reduction is larger that what would be expected by halving expression of the precursor of these fragments is unclear. However, this observation is interesting given the recent finding that $\beta$-CTF plays a pathogenic role in the Danish dementia (Tamayev et al., 2011a).

Next we tested whether reduced APP expression could rescue the behavioral deficits in $\mathrm{FBD}_{\mathrm{KI}}$ mice by restoring normal levels of mBRI2 expression. Interestingly, APP hemizygosity reduces mBRI2 expression both in mice WT for Bri2/Itm $2 b$ and $\mathrm{FBD}_{\mathrm{KI}}$ mice (Fig. 2D,E). These results further underline the close functional and biochemical relationship between APP and BRI2 and suggest that APP can stabilize BRI2. Regardless, they exclude that halving APP can restore normal mBRI2 functions.

\section{Discussion}

Here, we have investigated whether APP plays a role in the pathogenesis of memory impairments in $\mathrm{FBD}_{\mathrm{KI}}$ mice. The evidence of genetic suppression of cognitive deficits by APP haploinsufficiency shows that FBD pathogenesis is attributable to APP. Because BRI2 is a physiological inhibitor of APP processing, and given the loss of mature Bri2 in $\mathrm{FBD}_{\mathrm{KI}}$ mice, a possible interpretation of our data is that deregulation of APP processing causes memory loss in FBD (Fig. 3A). This model is supported by the analysis of a knock-in mouse model for the other familial dementia (Familial Danish dementia, FDD $_{\mathrm{KI}}$ mice; Giliberto et al., 2009) caused by mutation of the BRI2/ITM $2 b$ gene (Vidal et al., 2000). $\mathrm{FDD}_{\mathrm{KI}}$ mice present reduction in mature Bri2 levels in synaptic compartments (Tamayev et al., 2010a) and an increase in APP processing in the CNS (Matsuda et al., 2011a; Tamayev et al., 2011b). These animals develop progressive hippocampal memory deficits that are dependent on APP (Tamayev et al., 2011b) and, more specifically, on APP processing by $\beta$-secretase (Tamayev et al., 2011a). However, analysis of the whole brains of $\mathrm{FBD}_{\mathrm{KI}}$ mice did not reveal obvious signs of APP processing alterations (data not shown). It should be noted that the Danish mutation causes a more dramatic reduction in mature Bri2 levels in synaptic preparation; synaptic mature Bri2 is reduced by $\sim 80 \%$ in $\mathrm{FDD}_{\mathrm{KI}}$ mice and $\sim 25 \%$ in $\mathrm{FBD}_{\mathrm{KI}}$ animals (Tamayev et al., 2010a,b). Therefore, it is possible that APP processing is altered less dramatically in FBD, and that this reduction cannot be detected when analyzing the steady-state levels on endogenous APP metabolites in the CNS. The recent finding that memory deficits of $\mathrm{FDD}_{\mathrm{KI}}$ mice can be rescued by inhibiting $\beta$-secretase cleavage of APP (Tamayev et al., 2011a) supports this hypothesis. Alternatively, it could be postulated that APP, BRI2, and APP/BRI2 complexes deliver distinct signals. In FBD, an augmentation of APPsignaling and a reduction of BRI2-signaling and APP/BRI2signaling could lead to memory deficits (Fig. 3B). In both models, reducing APP load would reconstitute normal signaling.

In conclusion, here we show that endogenous APP is implicated in the pathogenesis of FBD. This evidence underlies strong analogies between FBD and Familial Alzheimer disease pathogenesis, where APP itself or genes that regulate APP processing (i.e., $P S E N 1 / 2$ ) are mutated. These data suggest that the $\mathrm{FBD}_{\mathrm{KI}}$ mice could prove useful to study the pathogenic mechanisms of APP and/or proteolytic APP products. Additionally, this mouse model could help in testing disease-modifying therapeutic intervention strategies for resulting dementias.

\section{References}

Bertram L, Lill CM, Tanzi RE (2010) The genetics of Alzheimer disease: back to the future. Neuron 68:270-281.

Bevins RA, Besheer J (2006) Object recognition in rats and mice: a one-trial non-matching-to-sample learning task to study 'recognition memory.' Nat Protoc 1:1306-1311.

Choi SI, Vidal R, Frangione B, Levy E (2004) Axonal transport of British and Danish amyloid peptides via secretory vesicles. FASEB J 18:373-375.

Diamond DM, Park CR, Heman KL, Rose GM (1999) Exposing rats to a predator impairs spatial working memory in the radial arm water maze. Hippocampus 9:542-552.

Fotinopoulou A, Tsachaki M, Vlavaki M, Poulopoulos A, Rostagno A, Frangione B, Ghiso J, Efthimiopoulos S (2005) BRI2 interacts with amyloid precursor protein (APP) and regulates amyloid beta (Abeta) production. J Biol Chem 280:30768-30772.

Giliberto L, Matsuda S, Vidal R, D’Adamio L (2009) Generation and initial characterization of FDD knock in mice. PLoS One 4:e7900.

Holton JL, Ghiso J, Lashley T, Rostagno A, Guerin CJ, Gibb G, Houlden H, Ayling H, Martinian L, Anderton BH, Wood NW, Vidal R, Plant G, Frangione B, Revesz T (2001) Regional distribution of amyloid-Bri deposi- 
tion and its association with neurofibrillary degeneration in familial British dementia. Am J Pathol 158:515-526.

Holton JL, Lashley T, Ghiso J, Braendgaard H, Vidal R, Guerin CJ, Gibb G, Hanger DP, Rostagno A, Anderton BH, Strand C, Ayling H, Plant G, Frangione B, Bojsen-Møller M, Revesz T (2002) Familial Danish dementia: a novel form of cerebral amyloidosis associated with deposition of both amyloid-Dan and amyloid-beta. J Neuropathol Exp Neurol 61:254-267.

Kilger E, Buehler A, Woelfing H, Kumar S, Kaeser SA, Nagarathinam A, Walter J, Jucker M, Coomaraswamy J (2011) BRI2 protein regulates $\beta$-amyloid degradation by increasing levels of secreted insulin-degrading enzyme (IDE). J Biol Chem 286:37446-37457.

Kim J, Miller VM, Levites Y, West KJ, Zwizinski CW, Moore BD, Troendle FJ, Bann M, Verbeeck C, Price RW, Smithson L, Sonoda L, Wagg K, Rangachari V, Zou F, Younkin SG, Graff-Radford N, Dickson D, Rosenberry T, Golde TE (2008) BRI2 (ITM2b) inhibits Abeta deposition in vivo. J Neurosci 28:6030-6036.

Kim SH, Creemers JW, Chu S, Thinakaran G, Sisodia SS (2002) Proteolytic processing of familial British dementia-associated BRI variants: evidence for enhanced intracellular accumulation of amyloidogenic peptides. J Biol Chem 277:1872-1877.

Matsuda S, Giliberto L, Matsuda Y, Davies P, McGowan E, Pickford F, Ghiso J, Frangione B, D'Adamio L (2005) The familial dementia BRI2 gene binds the Alzheimer gene amyloid-beta precursor protein and inhibits amyloid-beta production. J Biol Chem 280:28912-28916.

Matsuda S, Giliberto L, Matsuda Y, McGowan EM, D'Adamio L (2008) BRI2 inhibits amyloid beta-peptide precursor protein processing by interfering with the docking of secretases to the substrate. J Neurosci 28:8668-8676.

Matsuda S, Tamayev R, D'Adamio L (2011a) Increased A $\beta$ PP processing in familial Danish dementia patients. J Alzheimers Dis 27:385-391.

Matsuda S, Matsuda Y, Snapp EL, D'Adamio L (2011b) Maturation of BRI2 generates a specific inhibitor that reduces APP processing at the plasma membrane and in endocytic vesicles. Neurobiol Aging 32:1400-1408.

Rostagno A, Revesz T, Lashley T, Tomidokoro Y, Magnotti L, Braendgaard H, Plant G, Bojsen-Møller M, Holton J, Frangione B, Ghiso J (2002) Complement activation in chromosome 13 dementias. Similarities with Alzheimer's disease. J Biol Chem 277:49782-49790.

Tamayev R, Matsuda S, Fà M, Arancio O, D’Adamio L (2010a) Danish dementia mice suggest that loss of function and not the amyloid cascade causes synaptic plasticity and memory deficits. Proc Natl Acad Sci U S A 107:20822-20827.

Tamayev R, Giliberto L, Li W, d'Abramo C, Arancio O, Vidal R, D'Adamio L (2010b) Memory deficits due to familial British dementia BRI2 mutation are caused by loss of BRI2 function rather than amyloidosis. J Neurosci 30:14915-14924.

Tamayev R, Matsuda S, Arancio O, D'Adamio L (2011a) $\beta$ - but not $\gamma$-secretase proteolysis of APP causes synaptic and memory deficits in a mouse model of dementia. EMBO Mol Med 4:171-179.

Tamayev R, Matsuda S, Giliberto L, Arancio O, D’Adamio L (2011b) APP heterozygosity averts memory deficit in knockin mice expressing the Danish dementia BRI2 mutant. EMBO J 30:2501-2509.

Trinchese F, Liu S, Battaglia F, Walter S, Mathews PM, Arancio O (2004) Progressive age-related development of Alzheimer-like pathology in APP/ PS1 mice. Ann Neurol 55:801-814.

Vidal R, Frangione B, Rostagno A, Mead S, Révész T, Plant G, Ghiso J (1999) A stop-codon mutation in the BRI gene associated with familial British dementia. Nature 399:776-781.

Vidal R, Revesz T, Rostagno A, Kim E, Holton JL, Bek T, Bojsen-Møller M, Braendgaard H, Plant G, Ghiso J, Frangione B (2000) A decamer duplication in the $3^{\prime}$ region of the BRI gene originates an amyloid peptide that is associated with dementia in a Danish kindred. Proc Natl Acad Sci U S A 97:4920-4925. 